\title{
Pinguela: nossas novas travessias...
}

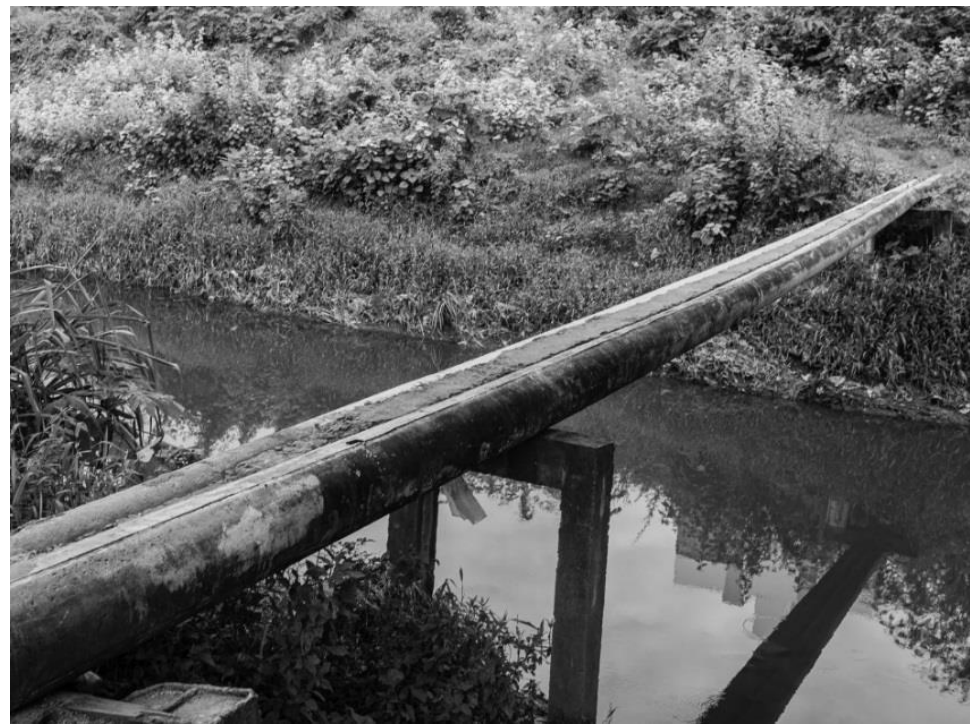

Pinguela - substantivo feminino

Ponte rústica e improvisada com paus ou troncos, sem proteção lateral. Transmite sensação de insegurança e exige coragem de quem se propõe a atravessá-la.

Com muita satisfação, a Motrivivência põe à disposição da comunidade acadêmica mais uma edição, a terceiro do ano de 2020. Esse número (v.32, n.63) é publicado em plena pandemia da COVID-19, no momento em que nosso país passa a marca das 80 mil mortes e alcança mais de 2 milhões de infectados pela doença. Continuamos a enfrentar, além dos agravos produzidos pelo coronavírus, as consequências deletérias de um mal maior, representado pela irresponsabilidade, pela ignorância, pela prepotência e pela ganância dos que se reúnem em torno do presidente da república e do seu necrogoverno. 
Parcela do sistema judiciário brasileiro, assim como algumas forças da direita não fascista, parecem ter despertado do longo pesadelo que é ter bolsonaro e a sua quadrilha no poder ${ }^{1}$. Os partidos e movimentos da esquerda progressista já há muito vinham denunciando que a paralisia política que blinda essa nefasta gestão tinha a cumplicidade do poder judiciário e da centro-direita neoliberal. Os mesmos que contribuíram, por ação ou por inanição, com o golpe de 2016 que resultou no impeachment da presidenta Dilma - e, a seguir, na prisão totalmente arbitrária do ex-presidente Lula. Foram eles, como sabemos, cúmplices da ascensão e vitória de um projeto político que anunciadamente pretendia destruir o estado democrático de direito e repor, com o expresso apoio de militares e civis órfãos da ditadura instalada a partir do golpe militar de 1964, o Brasil no caminho das trevas, de voltar a ser um país-pária no mundo.

Aos poucos, temos observado, como dissemos, ações mais pragmáticas de alguns desses setores, que mesmo não sendo confiáveis, parecem estar interessados em funcionar como um sistema de freios e contrapesos ao governo, um pouco para reduzir os malefícios causados pela ideologia destruidora que está no poder, um pouco, também, para se reposicionarem no cenário político, preservando-se numa distância prudente do governo, como se não fossem responsáveis por ele - e confiando na memória curta da sociedade brasileira. A todo momento, pipocam notícias no cenário político e judiciário contra a familícia que tomou de assalto o palácio do Planalto; denúncias são feitas, investigações são abertas, diligências são realizadas, provas são colhidas... É possível que, a medida em que as evidências forem se consolidando como crime, ocorra um grande acordão "por cima”, daqueles “com o supremo, com tudo"? É obvio que sim! Mais que isso, é muito provável. Derrubar a chapa bolsonaro-mourão ou colocar em debate a cassação do mandato de bolsonaro significaria o reconhecimento de que as esquerdas sempre estiveram certas. Que a eleição de 2018 foi uma fraude que contou com a conivência criminosa do TSE. Que os neoliberais oportunistas vão ter que esperar mais um pouco para leiloar o patrimônio do povo brasileiro. É por isso que exatos 49 (até esse momento!) pedidos de impeachment repousam solenes embaixo da bunda gorda do nhonhô, o botafogo das planilhas da Odebrecht, que hoje preside a Câmara dos Deputados.

De todo o modo, a simples agitação político-judicial que essas ações provocam pode representar uma pinguela, uma ponte rústica e improvisada, pouco segura, mas que implicaria uma redução do poder facínora quase monolítico que se instalou no poder, desde a onda fascista das eleições de 2018, do Planalto às assembleias legislativas estaduais, e que vem destruindo os direitos

\footnotetext{
${ }^{1}$ Poderíamos citar, como exemplo, o processo instaurado junto ao STF e a CPMI no Congresso, que visam identificar e indiciar os responsáveis pelo financiamento e pela propagação de fakenews, pratica sobejamente comandada pelo gabinete do ódio, na antessala do próprio presidente, no palácio do Planalto.
} 
de trabalhadores, servidores públicos, estudantes, negros, pobres, indígenas, comunidade LGBTQ, da saúde, da educação, da ciência e tecnologia, do meio ambiente, etc. É ainda exagero pensarmos nisso como uma travessia segura para outro momento, em que o debate democrático não seja contaminado pelos gabinetes do ódio, pelas fakenews, pela truculência, pelo autoritarismo e pela exploração da ignorância de parcela significativa da sociedade brasileira. Não temos motivos ainda para retirarmos uma expressão sequer da série de denúncias que fizemos em nossos editoriais anteriores. Mas precisamos, politicamente, centrar nossas forças nessas contradições, expô-las ao máximo, para que as rachaduras e fraturas desse muro, para nós sempre tão explícitas, sejam percebidas e possam quebrar, ainda que "por dentro", esse sistema bandido que tomou conta do país.

$* * * * * *$

No momento em que escrevemos esse editorial, começa no Brasil a testagem de duas vacinas decorrentes de pesquisa internacionais contra o coronavírus, e uma terceira acaba de receber autorização para realizar seus testes. Essa é uma daquelas situações em que experimentamos sentimentos diversos, ainda que não excludentes entre si.

Por um lado, há a esperança de que essas experiências sejam bem-sucedidas e que, num prazo razoável e de modo seguro, a humanidade venha a dispor dessa ferramenta biofarmacológica para enfrentar a pandemia do coronavírus. Ainda há muitas incertezas quanto à eficácia dessas pesquisas. Quanto tempo será preciso para chegarmos a resultados confiáveis? Quanto tempo ainda é necessário para a produção em larga escala da(s) vacina(s) e para a imunização das populações? Será que esses esforços mundiais, que reúnem aparatos públicos e privados, resultarão em um produto de qualidade e acessível a todos? Quantos contaminados e mortos ainda precisaremos contar até que esse ciclo terrível seja interrompido? Quantas vidas ainda vai nos custar a irresponsabilidade dos governos e de parcelas da população, que não incentivam nem respeitam o isolamento social, ou uso adequado de medidas sanitárias como uso de máscara e higienização frequente das mãos?

Aliás, esse é o outro lado da equação, do nosso copo "meio cheio" e "meio vazio". É humilhante sabermos que tais experiências e testagens de vacinas que começam a ocorrer no Brasil decorrem justamente da incapacidade política e social de nosso governo e da sociedade em conter a contaminação pelo vírus. Fomos escolhidos por esses laboratórios internacionais justamente porque nossos índices de morbidade e de letalidade são muito grandes e ainda crescentes; porque não tivemos a competência para frear socialmente a expansão vertiginosa do vírus com isolamento responsável; porque temos hoje o segundo maior número de afetados no mundo; porque entramos num processo 
continuado e muito alto de platô nos níveis de mortos pela COVID-19; enfim, somos hoje o lócus adequado para a testagem das vacinas porque não soubemos nos cuidar; porque agimos como negacionistas, contra todas as evidências e orientações científicas; porque nosso sistema público de saúde (SUS), nas mãos de duas dúzias de militares obtusos e neófitos, está à beira do colapso; por tudo isso (e só por isso) é que viramos, a exemplo das pequenas e precárias republiquetas da África profunda, nas décadas de 80 e 90 do século passado, um laboratório a céu aberto para a experimentação científica da indústria farmacêutica!

As vacinas que estão sendo testadas por aqui podem garantir uma travessia para chegarmos ao chamado "novo normal", uma esperança para que o mundo se reencontre consigo mesmo; para que as práticas sociais voltem a pautar nossa experiência comum, mesmo sabendo que muitas consequências dessa pandemia ainda irão repercutir e se fazer sentir por um longo tempo à frente. Ainda assim, com possibilidades e limites, essas testagens são, no momento, a pinguela que concentra em si as expectativas para uma travessia possível ao mundo.

$* * * * *$

Essa edição da Motrivivência inaugura uma nova sistemática de editoração. A exemplo de muitos outros periódicos científicos, estamos migrando para o modelo de publicação contínua. Isso significa que os textos serão publicados na edição aberta à medida que forem aprovados pelos nossos avaliadores. O presente número, então, representa uma situação de transição; nele estão sendo publicados, neste primeiro momento, um lote de 10 artigos submetidos nos meses de fevereiro e março e aprovados nos meses seguintes; no decorrer deste segundo semestre, outros grupos de textos irão sendo publicados para compor, ao final do ano, a edição v.32, n.63, 2020.

Para tanto, nossas rotinas editoriais, assim como aquelas que marcam nossos procedimentos junto ao Portal de Periódicos da BU/UFSC, tiveram que ser ajustadas; às vezes, até mesmo tendo que enfrentar os limites de uma plataforma digital (SEER/OJS) que, passados alguns anos da sua customização pelo IBICT/MCT, teve seu desenvolvimento e atualização descontinuados (mais uma evidência do poder destruidor desse desgoverno) e hoje já apresenta certas fragilidades e inconsistências, apesar do trabalho notável dos servidores da SeTIC/UFSC. Também foi preciso agilizar, ainda mais, o contato com os nossos avaliadores e pareceristas ad hoc, mobilizados por uma comissão editorial que, trabalhando intensamente e de forma remota, atua como uma equipe, enfrentando as novas demandas da editoração séria e responsável a que nos dedicamos. 
Estamos andando, pois, com alguma insegurança causada pela novidade, como sobre uma pinguela, que esperamos nos leve, na travessia, para outro patamar no periodismo científico do campo da Educação Física.

Essa mudança de sistemática implica diretamente sobre numa das nossas mais caras tradições: a produção de editoriais que se propõem a fazer verdadeiras análises de conjuntura do momento político, social, cultural, econômico do país. Com apenas uma edição anual, o que irá acontecer a partir de 2021, nós perderíamos a oportunidade de manifestar, a cada número da revista, nosso ponto de vista e a registrar, dessa maneira, nosso testemunho da história. Assim, para garantir que esse espaço de crítica continue existindo, desenvolvemos um novo canal de comunicação com nossos leitores, criando a seção Notas Editoriais. Nela, editores e comissão editorial da Motrivivência expressarão, em qualquer momento da edição, opiniões editoriais sobre temas relevantes ao campo da Educação Física, esporte e lazer e a toda a comunidade acadêmica e à sociedade como um todo.

Inauguramos a seção de Notas Editoriais na presente edição com um documento do qual a Motrivivência é signatária, denominado Carta de Porto Alegre. Nele, um conjunto de editores de periódicos acadêmicos da Educação Física, reunidos em Porto Alegre/RS, em novembro do ano passado, firma sua proposição de constituir um fórum permanente de editores da área e expressa sua crítica ao tratamento dispensado pela CAPES à política de editoração científica, incluindo a decisão unilateral de alterar o sistema Qualis, que atinge diretamente as revistas da Educação Física.

$* * * * *$

A imagem da pinguela que contempla nossa capa e que repetimos na abertura deste editorial expressa muito bem esse movimento permanente de encararmos novos desafios e de buscarmos nossas necessárias travessias - muito bem representado na foto mais uma vez gentilmente cedida pelo professor e fotógrafo Paulo Lima (a quem manifestamos nosso agradecimento). Ela também serve para representar as expectativas de que a justiça seja feita e o governo bolsonaro-mourão seja cassado e deposto; e que a vacina contra o coronavírus seja alcançada e disponibilizada para todos. Apesar da fragilidade da pinguela que essas expectativas ainda representam, queremos crer que é por meio dela que realizaremos a nossa travessia.

Nossa seção Homenagens abre espaço nessa edição para destacarmos o nosso reconhecimento e gratidão aos companheiros e companheiras do Portal de Periódicos da BU/UFSC, nossos parceiros já há 13 anos. Seus aconselhamentos, suas orientações técnicas, suas provocações e o respeito às nossas peculiaridades é o que possibilita a constante qualificação editorial da Motrivivência. 
Consideramos que nunca é demais repetirmos como somos gratos pela acolhida, pelo incentivo e pela inestimável contribuição dessas pessoas e instituições ao desenvolvimento do nosso projeto editorial.

Ao longo do texto desse editorial, temos falado muito em travessia. Vivemos todos, nesses tempos desconhecidos, a busca coletiva por travessias. Na política nacional, nessa crise sanitária e, no caso da Motrivivência, nessa nova fase editorial. Por isso, concluímos essas nossas reflexões com um trecho da música Travessia ${ }^{2}$, justamente aquele que explicita que somos nós mesmos que precisaremos nos reinventar para fazer a nossa travessia:

\section{$[\ldots]$}

Solto a voz nas estradas, já não quero parar

Meu caminho é de pedra, como posso sonhar

Sonho feito de brisa, vento vem terminar

Vou fechar o meu pranto, vou querer me matar

Vou seguindo pela vida me esquecendo de você Eu não quero mais a morte, tenho muito o que viver Vou querer amar de novo e se não der não vou sofrer Já não sonho, hoje faço com meu braço o meu viver

Florianópolis, julho de 2020.

\section{Mauricio Roberto da Silva, Giovani De Lorenzi Pires, Rogério Santos Pereira}

Editores

\footnotetext{
${ }^{2}$ Composição de Fernando Brandt e Milton Nascimento, a música integra o disco de mesmo nome, lançado por Milton Nascimento em 1967.
} 